\title{
COMPUTER GENERATION AND TESTING
} OF

RANDOM NUMBERS

\section{MASTER}

L. J. Gannon and L. A. Schmittroth

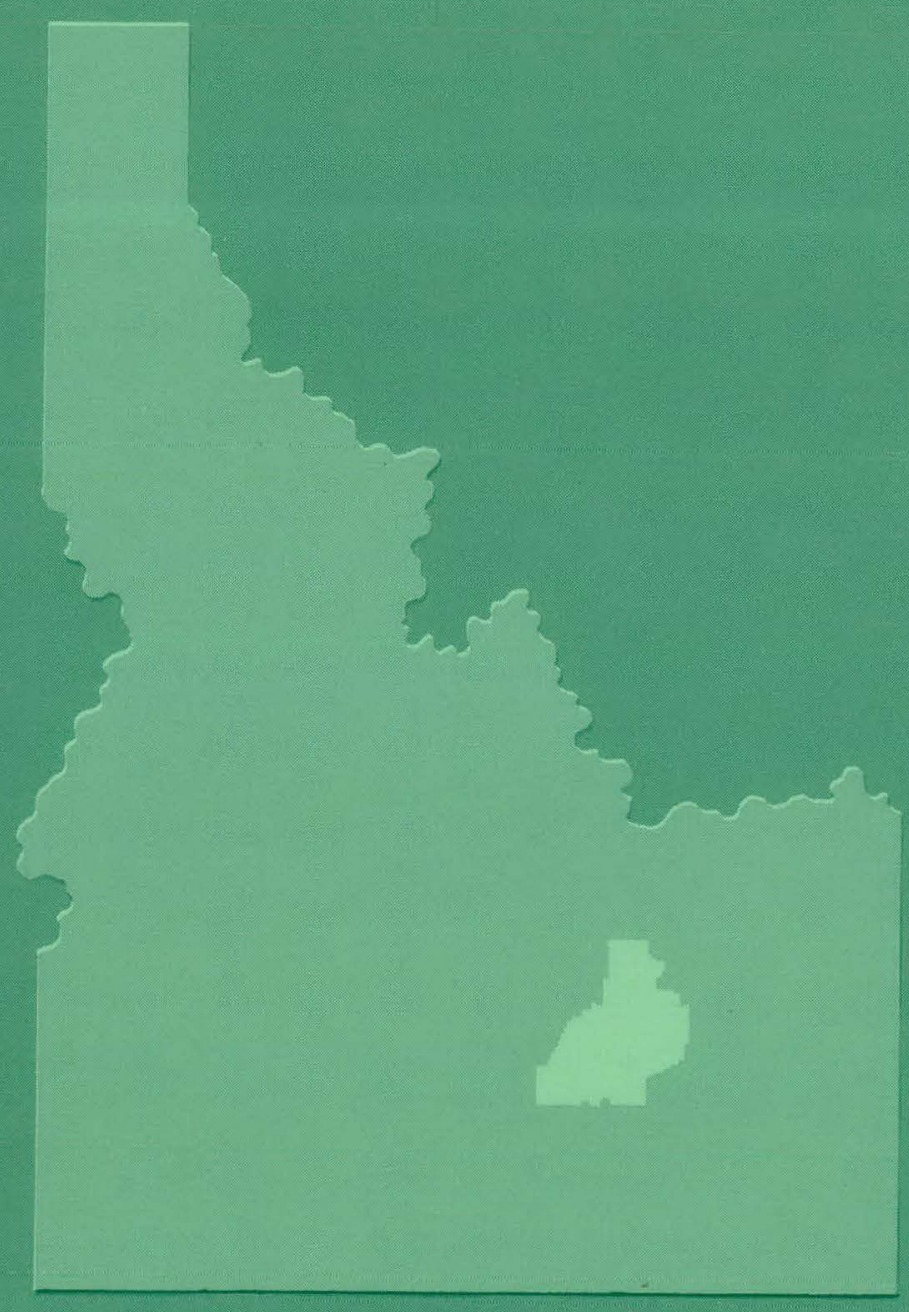

PHILLIPS PETROLEUM COMPANY

NATIONAL REACTOR TESTING STATION US ATOMIC ENERCY COMMISSION 


\section{DISCLAIMER}

This report was prepared as an account of work sponsored by an agency of the United States Government. Neither the United States Government nor any agency Thereof, nor any of their employees, makes any warranty, express or implied, or assumes any legal liability or responsibility for the accuracy, completeness, or usefulness of any information, apparatus, product, or process disclosed, or represents that its use would not infringe privately owned rights. Reference herein to any specific commercial product, process, or service by trade name, trademark, manufacturer, or otherwise does not necessarily constitute or imply its endorsement, recommendation, or favoring by the United States Government or any agency thereof. The views and opinions of authors expressed herein do not necessarily state or reflect those of the United States Government or any agency thereof. 


\section{DISCLAIMER}

Portions of this document may be illegible in electronic image products. Images are produced from the best available original document. 
PRICE \$1.00

\section{Available from the Office of Technical Services \\ U. S. Department of Commerce \\ Washington 25, D. C.}

\section{LEGAL NOTICE}

This report was prepared as an account of Government sponsored work. Neither the United States, nor the Commission, nor any person acting on behalf of the Commission:

A. Makes any warranty or representation, express or implied, with respect to the accuracy, completeness, or usefulness of the information contained in this report, or that the use of any information, apparatus, method, or process disclosed in this report may not infringe privately owned rights; or

B. Assumes any liahilities with regpect to thre usp uf, or far damages resulting from the use of any information, apparatus, method, or process disclosed in this report.

As used in the above, "person acting on behalf of the Commission" includes any employee or contractor of the Commission, or employee of such contractor, to the extent that such employee or contractor of the Commission, or employee of such contractor prepares, disseminates, or provides access to, any information pursuant to his employment or contract with the Commission, or his employment with such contractor. 
L. J. Gannon

I. A. Schmittroth

\section{PHILLIPS}

PETROLEUM

COMPANY

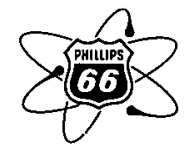

Atomic Energy Division

Contract AT(10-1)-205

Idaho Operations Office

U. S. ATOMIC ENERGY COMMISSION 


\section{THIS PAGE \\ WAS INTENTIONALLY LEFT BLANK}


COMPUTER GENERATION AND TESTING OF RANDOM NUMBERS

\section{Abstract}

This report discusses the need for random numbers particularly in regard to Monte Carlo applications and the two methods most commonly used to obtain random numbers. These methods are the multiplicative congruential method and the mixed congruential method, and both methods involve somewhat arbitrary parameters. Proofs for the lengths of period for both methods and a derivation of an expression for the serial correlation coefficient in terms of the parameters of the mixed congruential method are presented. The results of a series of statistical tests made to determine satisfactory parameters are listed. The length of run test was found to be the most powerful test in that it rejected the largest number of parameters as unsatisfactory. The multiplicative method (for the parameters tested) was found superior to the mixed congruential method. The multiplicative method multiplier $\lambda=2^{18}+3$ satisfactorily passed all tests and has a short multiply time. 
ABSTRACT . . . . . . . . . . . . . . . . . . . . . . ili

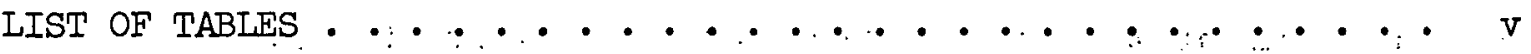

INTRODUCTION . . . . . . . . . . . . . . . . . • . . I

NEED FOR RAIDOM INUMBERS

Monte Carlo Method . . . . . . . . . . . . . . 1

Lxample of the Monte Carlo Method... . . . . . . . . . . 2

Traditional Sources of Random Numbers not Adequate . . . . . 3

Definition of Random Numbers . . . . . . . . . . . . . 4

DESCRIPTION OF TWO RAINDOM NUMBER GENERATORS : . • • . . . . : . $: 4$

Mid Square Method . ... . . . . . . .. . . . . 4

Multiplicative Congmuential Method . . . . . . . . . . 5

Mixed Congruential Method................... 5

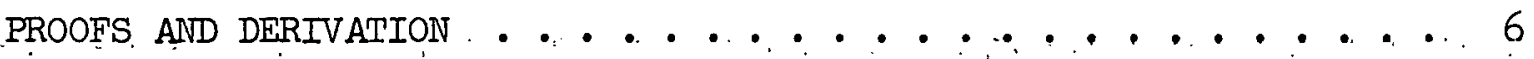

Length of Period for the Multiplicative Congruential Methods . 6

Length of Period for the Mixed Congruential Method ... . . . 9

Correlation Coefficient for the Mixed Congruential Method . . . 12

STATISTICAL TESTS . . • . . . . . . . . . . . . . 19

General Comments and Discussion of the Computer Program . . . 19

Frequency Test ...................... 21

Matrix Test .. . . . . . . . . . . . . . . . 22

Auto-correlation Coefficient . . . . . ...... 23

Frequency of Lengths of Runs . . . . . . . . . . . 24

Frequencies in Subsequences . . . . . . . . . . . 27

Conclusions . . . . . . . . . . . . . . . . . 28

LITRRATURE CITED . . . . . . . . . . . . . . . . . . 37 
1. Comparison of Chi-square Values of Frequencies in 1024 Subintervals with Generator Parameters ........... 30

2. Comparison of Chi-square Values of Frequencies in 32 by 32 Matrix with Generator Parameters . . . . ... . . . 31

3. Auto-correlation Coefficients . . . . . . . . . . . 32

4. Lengths of Runs . . . . . . . . . . . . . . . . . . 34

5. Chi-square Values of Frequencies in 1024 Subintervals, for 8 Subsequences of the Sequence Generated by Using

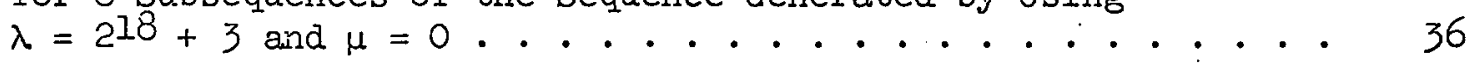




\section{INTRODUCTION}

Random numbers have been used for years in various statistical sampling techniques and have been obtained from different sources. With the development of high speed digital computers and the Monte Carlo method, interest has increased in random numbers, means of obtaining them, and various tests for randomiess.

This paper discusses the need for random numbers (particularly in regard to Monte Carlo applications) and the two methods most commonly used to obtain random numbers. These methods involve somewhat arbitrary parameters and this paper presents the results of statistical tests made to determine satisfactory parameters.

\section{NEED FOR RANDOM NUMBERS}

\section{Monte Carlo Method}

Random numbers drawn from a uniform distribution on the unit interval are required in a vide variety of both scientific and commercial applications. The colorful term Monte Carlo is commonly applied to any computation method that uses random numbers, and was first used by von Neumann and Ulam at Los Alamos in 1946. Nuclear Physicists have pioneered the use of Monte Carlo methods in the study of nuclear phenomena and in reactor calculations. Extensive use of the Monte Carlo method is now made in a wide variety of situations. In addition to the nuclear field some of the applications. include the studies of cell growth, traffic flow, scheduling, business, and 
social-economic systems. These types of problems are of a probabilistic nature and in some cases the Monte Carlo method has been the best method or the only method of attacking the problem. There is another class of problems that does not fall in this category, yet surprisingly the Monte Carlo method has been used with varying degrees of success in computing multiple integrals, solving differential and integral equations, finding eigenvalues, and inverting matrices.

Two basic requirements for the successful use of the Monte Carlo method are a high speed digital computer and a source of a large number of random numbers. The electronic computer has been in common use for about 10 or 15 years, and most of the investigation of random numbers has been in this period.

Example of the Monte Carlo Method

To illustrate how random numbers are used in the Monte Carlo method, we consider a nuclear reactor calculation. Here we simplify the problem to tracking a neutron as it collides and moves about in a region of the reactor. Let us suppose that" the region is composed of a homogeneous mixture of hyarogen, oxygen; aluminium, and uranium. Given that a neutron with a certain energy suffers a colitision with an isotope, the probability that the colitision will be with a particular isotope of the mixture can be computed from the concentrations and the cross 'sections. In our example 'let $P_{H}, P_{O}, P_{A I}$, and $P_{U}$ be these probabilities. "Then $\mathrm{P}_{\mathrm{H}}+\mathrm{P}_{\mathrm{O}}+\mathrm{P}_{\mathrm{AI}}+\mathrm{P}_{\mathrm{U}}=1$. We plot these in the unit interval as shown in Figure 1 .

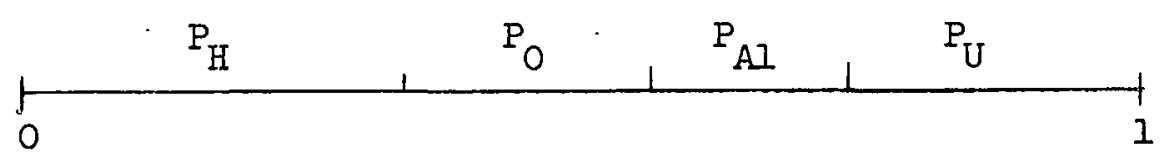

3. Fig. 1.--Plot of collision probabilities 
Then it is clear that drawing a random number from the unit interval and locating it in the proper position selects an isotope with the proper frequency. In other words if $0 \leq r \leq P_{H}$, where $r$ is a random number the collision is with $H_{\text {. }}$ If $\mathrm{P}_{\mathrm{H}}<r \leq \mathrm{P}_{\mathrm{H}}+\mathrm{P}_{\mathrm{O}}$, the collision is with 0 , etc. In a similiar manner a random number is used to determine the type of event, i.e., scattering, fission, or absorption, by comparing the random number to the probabilities of these events for the isotope involved in the collision. Random numbers are also used to determine the scattering angle, new direction cosines, and the distance to the next collision. Thus we see that in tracking a neutron many random numbers are used.

Traditional Sources of Random Numbers not Adequate

Conceptually randorn numbers can be obtained by tossing a coin, rolling dice, draving balls from urms, and similar actions which give rise to random events. However, these methods are much too slow to produce random numbers in the volume necessary for large scale calculations. Other physical sources of random numbers (mechanical equipment, pulses from electronic circuits, radioactive decay and other phenomena which give rise to random events) have not proved practical. There is a question if the source always produces "truly random" numbers, and it is impossible to exactly reproduce a given calculation. This requirement of being able to exactly reproduce a given calculation is extremely important and the comparision between solving the problem on the computer and working it out with pencil and paper can be made. One must be able to go back and check and recheck the intermediate steps, and always get the same answer to a given problem. If one gets two different answers to a problem, he can't tell which one is correct, or if either is correct. Thus algorithms have been developed by means of which sequences of "pseudo random" numbers can be produced and reproduced within the computer. 
Definition of Random Numbers

The concept of "pseudo-random numbers or sequence" has been defined by D. H. Lehmer [7] to be a "vague notion embodying the idea of a sequence in: which each term is unpredictable to the uninitiated and whose digits pass a certain number of tests traditional with statisticians and depending somewhat on the use to which the sequence is to be put."

H. Cramer [2] has stated, "It does not seem possible to give a precise detinition of' what is meant by the word 'random'." In the remainder of this paper the term random numbers will apply to both random numbers and pseudo-

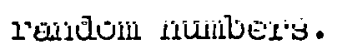

\section{DESCRIPTION OF TWO RANDOM NUMBER GEINERATORS}

The rather stringent requirements for a large number of random numbers, uniformly distributed, obtainable in a minimum of time, and exactly reproducible have been more or less satisfied by several algorithms or random number generators.

Mid Square Method

One of the first algorithms for producing random numbers was proposed by von Neumanin and Metropolis. This is the mid square method in which each number in the sequence is defined as the middle set of digits of the square. of the previous number. Consider as an example the first number in the sequence to be 1357 (assune we are working with four digit numbers). Then this number squared is 01841449 and the second number in the sequence is 8414 , the midale four digits of the squared number.

D. Lehmer [7] points out difficulties that have caused this method to be abandoned. Numbers of the type OOXY or XYOO soon develop and are either 
self perpetuating or quickly degenerate to zero. We will not consider this method in any more detail.

\section{Multiplicative Congruential Method}

D. H. Lehmer [7] proposed the multiplicative congruential method. His specific generator was

$$
x_{n+1} \equiv 23 x_{n}\left(\bmod 10^{8}+1\right)
$$

for a decimal machine with an eight digit word. (The word size of a computer is analogous to the keyboard capacity of a calculator.) That is, the random number $x_{n+1}$ is obtained from the random number $x_{n}$ by a multiplication. The multiplicative congruential method as most commonly now used is

$$
x_{n+1} \equiv \lambda x_{n}(\bmod P)
$$

Here $P=10^{b}$ or $2^{b}$ and $b$ is the number of digits or bits in the computer word. This modulus is chosen so that no division is necessary to form the congruence. Tho numbers of b bits ( $o r b$ digits) each are mutiplied to form a product of $2 \mathrm{~b}$ bits (or digits). The desired number consists of the $\mathrm{b}$ least significant bits (or digits). To avoid making the distinction between the binary and decimal computers, and bits and digits, only the binary computer will be considered in detail in what follows.

Mixed Congruential Method

A. Rotenberg: [8] proposed the mixed congruential method

$$
x_{n+1} \equiv \lambda x_{n}+\mu(\bmod P)
$$

This is similiar to the multiplicative method, only now a constant $\mu$ is added. Since the word length of the computer is finite, only a finite number of numbers can be represented. Also it is obvious that once a number in the 
sequence is repeated, a cycle is set up and the sequence from there on repeats itself. It is clear that we want a sequence with a long period (the number of numbers that are generated before a number is repeated).

As will be shown in the next section, the multiplicative congruential method has a maximium period of $2^{b-2}$ and this is obtained when the initial random number is odd and the multiplier has a value $\lambda \equiv \pm 3(\bmod 8)$. The mixed congruential method has a maximium period $2^{b}$ and is obtained with a multiplier $\lambda \equiv 2^{\mathrm{a}}+1, \mathrm{a}>2$, and the additive constant $\mu$ is odd.

The above calculations are performed in the computer with integer arithmëtic (as distinguished from floating point) and the fixed binary (decimal) point is assumed to be to the right of the right most bit during the calculation. Now since we want numbers on the unit interval, we merely reassign the binary point to the left of the left most bit and this gives the desired values $0<x_{n}<1$

PROOFS AND DERIVATION

Length of Period for the Multiplicative Method

In thie eection we want to determine a multiplier $\lambda$ and an initial number $x_{0}$ such that the multiplicative method

$$
x_{i+1} \equiv \lambda x_{i .}\left(\bmod 2^{b}\right)
$$

generates a sequence with the maximium period. We can make two preliminary observations. The first is that if the mutiplier $\lambda$ is even, i.e., $\lambda=2 k$, the period is very short. In fact

$$
x_{i+b} \equiv(2 k)^{b} x_{i}\left(\bmod 2^{b}\right)
$$


means that $x_{i+b}=x_{i}$ and that the sequence can not be longer than $b$. Hence, $\lambda$ must be odd in order to obtain a period of any useful length. Likevrise, if the initial number $x_{0}$ is even, the common factor 2 appears both in $x_{0}$ and the modulus $2^{b}$, hence, the modulus is effectively reduced, which reduces the period. Thus $x_{0}$ must also be odd.

To continue further we will need to recall several concepts and definitions from number theory. We do this and proceed as in [5].

Residue Class: A class of all integers which are mutually congruent for a given modulus. There are $\mathrm{m}$ distinct residue classes mod $\mathrm{m}$, corresponding to the terms of a complete residue system mod $\mathrm{m}$; collectively they comprise the class of all integers.

Complete Residue System: For a given modulus $\mathrm{m}$, a set of m numbers congruent in some order to the residues $0,1, \cdot \cdot \cdot \mathrm{m}-1$.

Reduced Residue System: A subset of a complete residue system, containing all terms which are relatively prime to $\mathrm{m}$.

Euler's phi-finction $\varphi(m)$ denoter the number of positive integers less than $m$ and prime to $m$, so a reduced residue system contains $\varphi(m)$ terms. If the prime factorization of $m$ is $m=\pi p_{i}^{e_{i}}$ (here II represents the product notation, $p_{i}$ the prime factors of $m$, and $e_{i}$ the number of times $p_{i}$ appears as a factor of $m)$, then $\varphi(m)=I\left(p_{i}-1\right) p_{i}^{e_{i}-1}$.

Power Residues: The residues of the successive powers of a number: $x^{n}$ " $(\bmod m)$ for $n=1,2,3, \cdots \cdot$

Order of $x \bmod m$ : When $x$ and $m$ are relatively prime, the least positive exponent $h$ with $x^{h} \equiv I($ mod $i l)$. Euler showed that $x^{\varphi(m)} \equiv I(\bmod m)$, from which it follows that $h$ is a divisor of $\varphi(m)$.

Primitive Root of $\mathrm{m}$ : $\Lambda$ number $\mathrm{x}$ whose order $\mathrm{h}=\varphi(\mathrm{m})$. 
The powers of a primitive root. $x$ generate a reduced system of residues mod $m$ (the largest possible set), and all primitive roots occur in this set. as powers whose exponents are relatively prime to $\varphi(\mathrm{m})$. Therefore, if $\mathrm{m}$ has: a primitive root, it has $\varphi(\varphi(\dot{m}))$ primitive roots, As an example consider $m=7$ and $x=3$, here the sequence is $3,2,6,4,5,1$ and then repeats. Note that all 6 positive integers less than 7 appear, showing that 3 is a primitive root of the prime modulus 7 . With the exception of $m=4$, only numbers of the form $\mu^{\mathrm{n}} \mathrm{u}_{1} \varepsilon^{\mathrm{Il}}$, for $\mathrm{p}$ all odd prime, have primitivo roote.

With this information we are now in a position to determine the maximum period and the corresponding requirement for the multiplier. We recall that the order.h of any number: $\lambda\left(\bmod 2^{b}\right)$ is a divisor of $\varphi\left(-2^{b}\right)=2^{b-1}$, (the number of odd positive integers less than $2^{b}$ ) and so is of the form $2^{e}$ for $\mathrm{e} \leq \mathrm{b}-1$. If $\mathrm{m}=2^{\mathrm{b}}$ had primitive roots e would equal $\mathrm{b}-1$, : however, $\mathrm{m}$ has no primitive roots ( $m$ is even and not 4 ) therefore, $e<b-1$. From our ear-: lier observation $\dot{\lambda}$ has to be odd, and we can represent all odd numbers in the form $8 t \pm 1$ or $8 t \pm 3$. We observe that

$$
(8 t \pm i)^{2^{b-3}}=1 \pm 2^{b} t+\cdots \cdot \equiv I\left(\bmod 2^{b}\right)
$$

So that the order of

$$
\lambda \equiv(8 t \pm 1)\left(\bmod 2^{b}\right)
$$

is a divisor of $2^{b-3}$, and any multiplier $\lambda \equiv 1(\bmod 8)$ will generate a sequence whose period is not greater than $2^{ن-j}$. We next show that a multiplier $\lambda \equiv 3(\bmod 8)$ leads to a sequence with a period greater than $2^{b-3}$.

$$
\begin{gathered}
( \pm 3+8 t)^{2^{b-3}}=3^{2^{b-3}} \pm 2^{b-3} \cdot 3^{2^{b-3}-1} \cdot 8 t+\cdots \cdot 3^{2^{b-3}}\left(\bmod 2^{b}\right) \\
\cdots \equiv(4-1)^{2^{b-3}} \equiv 1-2^{b-1} \neq 1\left(\bmod 2^{b}\right)
\end{gathered}
$$


This shows that the order of $\lambda \equiv 3(\bmod 8)$ is greater than $2^{\mathrm{b}-3}$. We then try $2^{b-2}$

$$
\begin{aligned}
( \pm 3+8 t)^{2^{b-2}} & =3^{2^{b-2}} \pm 2^{b-2} \cdot 3^{2^{b-2}-1} \cdot 8 t+\cdots \cdot \cdots 3^{2^{b-2}}\left(\bmod 2^{b}\right) \\
& \equiv(-1+4)^{2^{b-2}} \equiv 1\left(\bmod 2^{b}\right)
\end{aligned}
$$

So the order of $x \equiv 3(\bmod 8)$ is $h=2^{b-2}$. In our earlier discussion we saw that the order $h$ must divide $\varphi(m)=2^{b-1}$ and must be less than $2^{b-1}$. Hence, $h=2^{b-2}$ is the maximum order and corresponds to the maximum period of the multiplicative congruential method with a choice of a multiplier $\lambda \equiv 3$ (mod 8) and the initial number odd.

A final remark must be made concerning the multiplicative method. If random bits (or digits) are required, they should be taken from the left most (high-order) end, because the right most (low-order) bits are far from random.

Length of Period for the Mixed Congruential Methods

Recall that the mixed congruential method

$$
x_{n+1} \equiv \lambda x_{n}+\mu\left(\bmod 2^{b}\right)
$$

is similiar to the multiplicative method, only now a constant $\mu$ is added. As in the previous section, we now determine the maximum period for the mixed method and the requirements on $\lambda$ and $\mu$ to obtain the maximum period.

The following lemma is used in the proof of the maximum period of the mixed congmuential method.

Lemma:

$$
x_{i+n} \equiv \lambda^{n} x_{i}+\mu \frac{\lambda^{n}-1}{\lambda-1}(\bmod M)
$$

We prove this by induction. It is by definition true for $n=1$.

$$
x_{i+1} \equiv \lambda x_{i}+\mu(\bmod M)
$$


We assume it is true for case in,

$$
x_{i+n} \equiv \lambda^{n} x_{i}+\mu \frac{\lambda^{n}-1}{\lambda-1}(\bmod M)
$$

Then prove it for case $n+1$.

$$
\begin{aligned}
x_{i+n+1} & \equiv \lambda x_{i+n}+\mu(\bmod M) \\
& \equiv \lambda\left(\lambda^{n} x_{i}+\mu \frac{\lambda^{n}-1}{\lambda-1}\right)+\mu(\bmod M) \\
\because \quad & =\lambda^{n+1} x_{i}+\mu \frac{\lambda^{n+1}-\lambda}{\lambda-1}+\mu \frac{\lambda-1}{\lambda \cdot I}(\bmod M) \\
& \equiv \lambda^{n+1} x_{i}+\mu \frac{\lambda^{n+1} I}{\lambda-1}(\bmod M)
\end{aligned}
$$

This lemma is used in the proof of the maximum period which follows and can be used to extend the lag in the serial correlation coefficient which is discussed Iater.

To continue the proof of the maximum period, it is clear that the sequence repeats when $x_{1}=x_{1+n}$. Thus the problem is to find the minimum value of $\mathrm{n}$ for which the sequence repeats itself and this is the maximum period.

Thus

$$
x_{1}=x_{i+n} \equiv \lambda^{n} x_{i}+\mu \frac{\lambda^{n}-1}{\lambda-1}(\bmod M)
$$

tollows from the lemma. Subtract $x_{i}$ from each side uf the cunpruence and factor

$$
0 \equiv\left(\lambda^{n}-1\right) x_{i}+\mu \frac{\lambda^{n}-1}{\therefore \lambda-1}(\bmod M)
$$

Factor and bring to a common denominator

$$
0 \equiv\left(\frac{\lambda^{n}-1}{\lambda-1}\right)\left(x_{i}(\lambda-1)+\mu\right) \quad(\bmod M)
$$

Recalling that $\lambda=2^{a}+1, a \geq 2$, and that $\mu$ is odd we obtain.

$$
0 \equiv\left(\frac{\left(2^{a}+1\right)^{n}-1}{2^{a}}\right)\left(2^{a} x_{i}+\mu\right)\left(\bmod 2^{b}\right)
$$


The second factor is odd, since $\mu$ is odd, and the first factor must be divisible by $2^{b}$ to satisfy the congmence. This is equivalent to

$$
\left(2^{a}+1\right)^{n} \equiv 1\left(\bmod 2^{b+a}\right)
$$

Writing the congruence as an equation we obtaj.n

$$
\left(2^{a}+1\right)^{n}-1=m 2^{b+a}
$$

where $m$ is a positive integer. Expanding the first term, we have

$$
\sum_{k=2}^{n}\left(\begin{array}{l}
n \\
k
\end{array}\right) 2^{a k}+n \cdot 2^{a}+1-1=m 2^{b+a}
$$

where $\left(\begin{array}{l}n \\ k\end{array}\right)$ are the binomial coefficients $\frac{n !}{(n-k) ! k !} \cdot$ Dividing by $2^{b+a}$ yields

$$
\sum_{k=2}^{n}\left(\begin{array}{l}
n \\
k
\end{array}\right) 2^{a(k-1)-b}+n \cdot 2^{-b}=m
$$

We let $\dot{n}=r 2^{s}$, and $k=t 2^{i}$, where $t$ and $r$ are odd, and then use these substitutions to express the binomial coefficient in the form

$$
\left(\begin{array}{l}
n \\
k
\end{array}\right)=\frac{n}{k}\left(\begin{array}{l}
n-1 \\
k-1
\end{array}\right)=\frac{r}{\dot{t}}\left(\begin{array}{l}
n-1 \\
k-1
\end{array}\right) \cdot \frac{2^{s}}{2^{i}}=\text { an integer (a binomial coefficient). }
$$

We use this expression for the binomial coefficient and the substitutions to rewrite (1.2) in the following form.

$$
\left.m=\sum_{k=2}^{n} \frac{r}{t} \mid \begin{array}{l}
n-1 \\
k-1
\end{array}\right) \cdot \frac{2^{s}}{2^{i}} \cdot 2^{a\left(t 2^{i}-1\right)-b}+r \cdot 2^{s} \cdot 2^{-b}
$$

Now factor $a 2^{s-b}$ to obtain

$$
m=\left[\sum_{k=2}^{n} \frac{r}{t}\left(\begin{array}{l}
n-1 \\
k-1
\end{array}\right) \frac{2^{a\left(t 2^{i}-1\right)}}{2^{i}}+r\right] \cdot 2^{s-b}
$$

Since $\left(\begin{array}{l}n \\ k\end{array}\right)$ is an integer, the first term is an integer except possibly for a factor of 2. However, 


$$
\frac{2^{a\left(t 2^{i}-1\right)}}{2^{i}}=2^{a\left(t 2^{i}-1\right)-i}>1
$$

since $a>1, t$ is a positive integer, $i$ a non negative integer, and $t>2$ if $i=0$, so that the exponent of 2 is a positive integer. Hence, the first term in the brackets of (1.3) is even, and since $r$ is odd, the quantity in the brackets is odd. Hence, $s \geq b$ for $m$ to be an integer, hence, $n=2^{b}=$ the period for the mixed congruential method (recall that $b$ is the number of bits in the computer word). Thus we see that the mixed methods have a larger period than the multiplicative method. This is of little practical concerm, however, as it would take the IBM.709 computer over three months of steady computing to generate the maximum sequence for the multiplicative method.

\section{Correlation Coefficient for the Mixed Congruential Method}

The correlation coefficient $\rho$ serves as a measure of a property. of a distribution that might be called the degree of linear dependence between variables. For the mixed congruential method Coveyou lif first derived an approximate formula for the correlation coefficient in terms of the parameters $\lambda$ dud $\mu$. This represents the most significant step in relating the statistical properties of the generated sequence to the parameters of the generator. Coveyou's approximation was improved by Greenberger [4], and we present his derivation in what follows.

The correlation coefficient is defined to be

$$
\rho=\frac{\alpha-m_{1} \cdot m_{2}}{\sigma_{1}^{\prime} \cdot \sigma_{2}} \text {. }
$$

We will compute $\rho\left(x_{n}, x_{n+1}\right)$ for the full sequence of random numbers $\left(x_{n}\right)$ generated by the method $x_{n+1} \equiv \lambda x_{n}+\mu(\bmod P)$, where $\lambda$ and $\mu$ are chosen so that the period is $\mathrm{P}=2^{\mathrm{b}}$. 


$$
m_{1}=m_{2}=E\left(x_{n}\right)=E\left(x_{n+1}\right)
$$

is the expected or mean value of $x_{n}$, and

$$
\sigma_{1}=\sigma_{2}=\sqrt{E\left(x_{n}^{2}\right)-\left(E\left(x_{n}\right)\right)^{2}}
$$

is the standard deviation.

$$
\alpha=E\left(x_{n}, x_{n+1}\right)
$$

is the expected or mean value of $x_{n} x_{n+1}$. Equation (2.1) now becomes

$$
\rho=\frac{E\left(x_{n}, x_{n+1}\right)-\left(E\left(x_{n}\right)\right)^{2}}{E\left(x_{n}^{2}\right)-\left(E\left(x_{n}\right)\right)^{2}} .
$$

Values for $E\left(x_{n}\right)$ and $E\left(x_{n}^{2}\right)$ are readily obtained.

$$
\begin{aligned}
& E\left(x_{n}\right)=\sum_{x=0}^{P-1} x=\frac{P-1}{2} \\
& E\left(x_{n}^{2}\right)=\sum_{x=0}^{P-1} x^{2}=\frac{(P-1)}{6}(2 P-1)
\end{aligned}
$$

To obtain an expression for $E\left(x_{n}, x_{n+1}\right)$, equate $x_{n+1}$ with the remainder $x_{n}$ in the following equation.

$$
\lambda x_{n}+\mu=q_{n} P+r_{n} \quad(n=0,1, \cdot \cdot \cdot)
$$

where $q_{n}$ and $r_{n}<P$, and are non-negative integers, uniquely determined for each $x_{n}$ by the Euclidean algorithm. Omitting the subscript in (2.5) for converience we obtain

$$
\begin{aligned}
E\left(x_{n}, x_{n+1}\right) & =\frac{1}{P} \sum_{x_{n}=0}^{P-1} x_{n} x_{n+1}=\frac{1}{P} \sum_{x=0}^{P-1} x(\lambda x+\mu-q P) \\
& =\lambda E\left(x^{2}\right)+\mu E(x)-\sum_{x=0}^{P-1} x q
\end{aligned}
$$


The first two terms are easily evaluated, while the evaluation of $\sum x q$ presents a problem. We now work out an expression for the value of $\sum$ xq.......

Let $x_{n}$ in (2.5) take on consecutive integral values starting with zexo, and define

$$
\lambda \bar{x}_{\mathrm{q}}+\mu=\mathrm{q} P+\bar{r}_{\mathrm{q}}:
$$

Here $\bar{x}_{\mathrm{q}}$ is the initial (and smallest) $x$ and $\overline{\dot{r}}_{\mathrm{q}}$ is the smallest $r$ for a given value of $q$. By virtue of its being the smallest of its set, $\bar{r}_{\mathrm{q}}<\lambda$, except when $q=0$, and then $\bar{r}_{0}=\mu$. For $q=1, z_{1} \therefore \lambda$, we note that $\bar{r}_{q}$ is the unique non-negative integer less than $\lambda$ defined by

$$
\bar{r}_{q} \equiv \mu-q P(\bmod \lambda) \text {. }
$$

It follows that the integers, $\bar{r}_{q}$, are distinct and $\left(\bar{r}_{1}, \bar{r}_{2}, \cdot \cdot, \bar{r}_{\lambda}\right)$ are a permutation of the integers $(0,1,2, \cdots, \lambda-1)$. Later we will use the following inequalities involving $\left(\bar{r}_{1}, \bar{r}_{2}, \cdot \bar{r}_{\lambda}\right)$

$$
\sum_{q=1}^{\lambda} q(\lambda-q) \leq \sum_{q=1}^{\lambda} \bar{r}_{q} \dot{\vdots} \leq \sum_{q=1}^{\lambda} q(q-1) .
$$

or

$$
\frac{\lambda^{3}}{\zeta}-\frac{\lambda}{\zeta} \leq \sum_{q=1}^{\lambda} \bar{r}_{q} q \leq \frac{\lambda^{3}}{5}-\frac{\lambda}{5} .
$$

These relationships result from repeated application of a basic inequality which we state in terms of integers $k_{1} \leq k_{0}$, and $\ddot{k}_{3} \leq k_{4}$.

$$
k_{1} k_{4}+k_{2} k_{3} \leq k_{1} k_{3}+k_{2} k_{4}
$$

which fulluws from:

$$
\left(k_{2}-k_{1}\right)\left(k_{4}-k_{3}\right) \geq 0
$$

To demonstrate the application of (2.11) in obtaining (2.9), assume the contrary, i.e., 


$$
\sum_{q=1}^{\lambda} \bar{r}_{q} q>\sum_{q=1}^{\lambda} q(q-1)
$$

Expand this sumation and write

$$
\bar{r}_{1} \cdot 1+\cdots+\bar{r}_{j}+\cdots \bar{r}_{\lambda} \lambda>0 \cdot 1+1 \cdot 2+\cdots(j-1) j+\cdots(\lambda-1) \lambda
$$

Now assume $\bar{r}_{\lambda} \neq \lambda-I$ (otherwise we could cancel the last term on each side) and that $\bar{r}_{j}=\lambda-1$. We therr have $\bar{r}_{\lambda}<\bar{r}_{j}$ and can use (2.11) to write

$$
\bar{r}_{\lambda} \lambda+\bar{r}_{j}^{j} \geq \bar{r}_{\lambda}^{j}+\bar{r}_{j} \lambda
$$

Interchanging $\bar{r}_{j}$ and $\bar{r}_{\lambda}$ will strengthen the assumed inequality (2.13). Then the last term in each sequence, $(\lambda-1) \lambda$, can be cancelled and process repeated until all except the first terms are cancelled which state that zero is greater than a positive integer, a contradiction. Hence, our assumption (2.13) was false. In a similar manner it follows that

$$
\sum_{q=1}^{\lambda} q(\lambda-q) \leq \sum_{q=1}^{\lambda} \bar{r}_{q} q
$$

We now return to the evaluation of $\sum x q$ in (2.6). We can picture $q$ as a function of $x$ as a bar graph where the abscissa represents the $x$ values which min from zero to $P-I$, and the ordinate represents the $q$ values which run from zero to $\lambda$ for the case $\mu \geq \lambda$ (and to $\lambda$-1 for the case $\mu .<\lambda$ which we will consider later). For $\bar{x}_{q} \leq x<\bar{x}_{q+1}$ the function has the value $q$. So

$$
\sum_{x=0}^{P-1} x q=\sum_{q=1}^{\lambda} q \sum_{x=\bar{x}_{q}}^{\bar{x}_{q+1}-1} x .
$$

Graphically this is summing over the vertical bars of the bar graph. An equivalent and more convenient form, which can be considered as summing over 
the horizontal bars of the graph, is

$$
\begin{aligned}
\sum_{x=0}^{R=1} x q & =\sum_{q=1}^{\lambda} \sum_{x=x_{q}}^{P-1} x \\
& \left.=\frac{1}{2} \sum_{q=1}^{\lambda} P(P-1)-\bar{x}_{q}\left(\bar{x}_{q}-1\right)\right) \\
& =\frac{1}{2} \lambda P^{2}-\frac{\lambda P}{\rho}-\frac{1}{2} \sum_{q=1}^{\lambda} \bar{x}_{q}\left(\bar{x}_{q}-1\right) .
\end{aligned}
$$

Rer.alling from $(2.7)$ that

$$
\bar{x}_{q}=\frac{I}{\lambda}\left(P q+\bar{r}_{q}-\mu\right)
$$

and substituting in (2.18) we obtain

$$
\begin{gathered}
\sum_{x=0}^{P-1} x q=\frac{\lambda P^{2}}{2}-\frac{\lambda P}{2}-\frac{\mu^{2}}{2 \lambda}-\frac{\mu}{2}-\frac{p^{2}}{2 \lambda^{2}} \sum_{q=1}^{\lambda} q^{2}+P \frac{\lambda+2 \mu}{2 \lambda^{2}} \sum_{q=1}^{\lambda} q-\frac{1}{2 \lambda^{2}} \sum_{q=1}^{\lambda} \bar{r}_{q}^{2} \\
+\frac{\lambda+2 \mu}{2 \lambda^{2}} \sum_{q=1}^{\lambda} \bar{r}_{q}-\frac{p}{\lambda^{2}} \sum_{q=1}^{\lambda} \bar{r}_{q} q .
\end{gathered}
$$

From the definition of $\bar{r}_{\mathrm{q}}$. in (2.19) it follows that

$$
\sum_{q=1}^{\lambda} \bar{r}_{q}^{2}=\sum_{q=1}^{\lambda-1} q^{2}
$$

and that

$$
\sum_{q=1}^{\lambda} \bar{r}_{q}=\sum_{q=1}^{\lambda-1} q .
$$

Evaluating all the sumations of (2.20) except the last, and combining like terms yields 
$\sum_{x=0}^{P-1} x q=\frac{\lambda P^{2}}{3}-\frac{\lambda P}{4}-\frac{\mu^{2}}{2 \lambda}+\frac{P}{4}-\frac{\mu}{2 \lambda}+\frac{\mu P}{2 \lambda}+\frac{\lambda}{12}+\frac{\mu P}{2}-\frac{1}{12 \lambda}-\frac{P^{2}}{4}-\frac{P^{2}}{12 \lambda}-\frac{P S}{\lambda^{2}}$

where

$$
s=\sum_{q=1}^{\lambda} \vec{r}_{q} q
$$

Rewrite (2.2), using (2.3), (2.4), and (2.6).

$$
\begin{aligned}
\rho & =\frac{E\left(x_{n}, x_{n+1}\right)-\left(E\left(x_{n}\right)\right)^{2}}{E\left(x_{n}^{2}\right)-\left(E\left(x_{n}\right)\right)^{2}} \quad \\
& =\frac{\lambda E\left(x_{n}^{2}\right)+\mu E(x)-\left(E\left(x_{n}\right)\right)^{2}-\sum_{x=0}^{P-1} x q}{E\left(x_{n}^{2}\right)-\left(E\left(x_{n}\right)\right)^{2}} \\
& \left.=\frac{12\left(\frac{\lambda}{\sigma}(P-1)(2 P-1)+\frac{\mu}{2}(P-1)-\frac{1}{4}(P-1)(P-1)-\sum_{x=0}^{P-1} x q\right.}{2(P-1)(2 P-1)-3(P-1)(P-1)}\right)
\end{aligned}
$$

Carry out the division by $\mathrm{P}^{2}-1$, the denominator in (2.25), using the value for $\sum x q$ in $(2.23)$ and neglect terms whose order of magnitude is $1 / P$ or less. This yields the correlation coefficient which we set out to determine

$$
\rho\left(x_{n}, x_{n+1}\right) \doteq \frac{1}{\lambda}-\frac{\sigma_{\mu}}{\lambda P}\left(1-\frac{\mu}{P}\right)+\frac{12}{P}\left(\frac{S}{\lambda^{2}}-\frac{\lambda}{4}\right) .
$$

ํ. is usually of the order of $10^{10}$ so that the approximation $(\fallingdotseq)$ is an equality for all practical purposes: Recalling that.

$$
s=\sum_{\mathrm{q}=0}^{\lambda} \bar{r}_{\mathrm{q}} \mathrm{q}
$$


and (2.10) we can set limits on $S$ and the last term of (2.26).

$$
\frac{\lambda}{6}\left(\lambda^{2}-1\right) \leq S \leq \frac{\lambda}{3}\left(\lambda^{2}-1\right)
$$

Multiply equation (2.27) by $12 / \lambda^{2}$, add $3 \lambda$, and divide by $P$. to obtain

$$
\frac{-\lambda}{\mathrm{P}} \leq \frac{12}{\mathrm{P}}\left|\frac{\mathrm{S}}{\lambda^{2}}-\frac{\lambda}{4}\right| \leq \frac{\lambda}{\mathrm{P}}
$$

where terms of magnitude less than $1 / P$ are omitted.

We return now to the case $\mu<\lambda$. Using the same approach and recalling the comment prior to (2.17), we again obtain (2.23), only now with a slightly different value for $S$. Because $\mu<\lambda$ and of the magnitude of $P$, (2.26) then reduces to

$$
\rho\left(x_{n}, x_{n+1}\right) \doteq \frac{1}{\lambda}+\frac{12}{P}\left(\frac{s}{\lambda^{2}}-\frac{\lambda}{4}\right)
$$

where

$$
3=\sum_{q=1}^{\lambda-1} \bar{r}_{q} q
$$

and the inequality (2.28) again holds; The values of $S$ as given by (2.24) an (2.30) corresponding to $\mu \geq \lambda$ an $\mu<\lambda$ differ in definition by the upper limit on the summation $(\lambda$ and $\lambda-1)$ and hence only by a negligible amount: We conclude our discussion and derivation of the serial correlation coefficient by mentioning several additional items. The first is that the results obtained above can be readily used for computing the correlation coefficient for any order $n$. This can be done by using the results of lemma (1.1) in (2.26) where $\lambda$ is replaced by $\lambda^{n}$ and $\mu$ is replaced by $\mu \frac{\lambda^{n}-1}{\lambda-1}$. Another point is that a small correlation coefficient is not a sufficient condition for randomness. An example will be given shortly. Also, the above derivation assumes that the whole sequence is generated, something 
that is never done in practice. Certain subsequences may be far from random. This is demonstrated by the using $\lambda=2^{18}+1, \mu=1, x_{0}=1$, and $P=2^{35}$. Substituting these values for $\lambda$ and $\mu$ in (2.29) yields a value for $\rho$ of less than $10^{-5}$. Yet the first several hundred numbers in the sequence are less than $P / 2$ which is far from random [3].

Thus (2.29) can be used for picking possible values for $\lambda$ and $\mu$, yet the sequence produced must still be carefully checked. The sequence should be subjected to certain standard tests and also checked in the light of. Lehmer's definition ". - depending somewhat on the use to which the sequence is to be put."

\section{STATISTICAL TESTS}

\section{General Comments and Discussion of the Computer Program}

There are many possible tests for randomness. In keeping with the spirit of Lehmer's definition, we have selected the tests described in the following sections chiefly because of their acceptance as standard and because of Monte Carlo applications. In most Monte Carlo appiications one is more interested in random numbers than in random digits. That is, the random number appears as a multiplier or additive constant and only a few digits of the result are significant, or a few leading bits or digits are used as an index to pick a quantity from a table. Thus we are not considering the usual tests for randomness of digits.

A computer program was written in the FAP language for the IBM 709/ 7090 to test random number generators. The test is actually a series of tests which are performed on the sequence of numbers as they are generated. The input for the computer program consists of the sample size, the initial random number, the multiplier $\lambda$, the constant $\mu$ (these last three numbers are 
specified in octal), and the number of samples. The sample size is the number of numbers that are generated by a set of parameters ( $\lambda$ and $\mu$ ) and subjected to the series of tests. A sample size of 10,240 was used in all but one test.:

The initial random number is the number used to obtain the first number in the sequence. The number $123456227651_{8}$ (the subscript 8 indicates an octal number) was used to start the first sequence for each set of parameters, with one exception which is noted later. The last number in any sequence or sample was used as the initial number for the following sequence generated by the same parametiers.

Our main concern is to determine suitable parameters $\lambda$ and $\mu$. For the multiplicative method $\mu=0$ and hence the tests are only for the multiplier $\lambda$. Three multipliers for the multiplicative method were tested. Various computing installations use these multipliers and one would expect them to be satisfactory, as indeed the following tests demonstrate.

For the mixed methods multipliers of the type $\lambda=2^{a}+1$ were tested. Here we were looking tor a multiplier with only a f'ew bits and consequently a fast multiplier. To illustrate this, the computer can multiply $1.637_{R}$ by $1001_{R}$ faster than it can multiply $1637_{8}$ by $5714^{\circ}$. To test a range of multipliers we held $\mu=: I$ for all but one multiplier. The different $\mu$ value had an appreciable effect on the resulting statistics. However, there are $2^{34}-1$ possible values of $\mu$ that could be used with a $\lambda$ value and it seemed more profitable to vary $\lambda$ than $\mu$.

One generator $\lambda=2^{34}+1$ and $\mu=1$, has been mentioned [4] as unsatisfactory and was ineluded to see how this would show up in the tests. One can notice in the following sections that it is definitely unsatisfactory.

About one minute of 709 computer time is required for a sample of 10,240 numbers. 
The last item for input to the computer program is the number of samples. Three samples of 10,240 were used to test all the generators considered, and the results of the test on these samples, are presented in tables in the following sections. Nine additional samples of 10,240 were tested, for each of . two generators. For some simplification of discussion in the following sections we shall refer to these tests on the adjional samples as the "extended tests on MI and M2." We define MI to be $\lambda=2^{18}+3$ with $\mu=0$ and M2 to be $\lambda=2^{9}+1$ with $\mu=1$.

\section{Frequency Test}

A good random number generator is expected to distribute the numbers uniformly on the unit interval. To test this distribution we divide the unit interval into $K$ subintervals (in our test $K=1024$ ); then generate $N$ numbers (this corresponds to our sample size of 10,240) and count or tally the number of times a number appears in each subinterval. In the computer program the 10 leading bits of a number are used as an index to determine the proper subinterval.

The expected number in each subinterval is $E=N / K=10,240 / 1024=10$. To test the deviation from the expected value we compute the chi-square value

$$
x^{2}=\sum_{i=1}^{K} \frac{\left(f_{i}-E_{i}\right)^{2}}{E_{i}}=\sum_{i=1}^{K} \frac{\left(f_{i}-\left.10\right|^{2}\right.}{10}=\frac{1}{10} \sum_{i=1}^{1024}\left(f_{i}-\left.10\right|^{2}\right.
$$

where $f_{i}$ is the observed frequency in subinterval $i$. We then compare this chisquare value with the chi-square distribution with 1023 degrees of freedom which has a 9.5 per cent confidence interval of $936.3 \leq x^{2} \leq 1113.5$. Table I lists these computed chi-square values as a function of the generator parameters. We make the following observations on the contents of Table 1 :

Three of the generators have one value that is slightly low, one set 
of values is consistently low, and two sets are way off scale. We had anticipated excessive values with $\lambda=2^{34}+1$ and $\mu=i$. However, the chi-square value of zero for $\lambda=2^{12}+1$ and $\mu=1$ is rather surprising: This means that this generator placed the expected number in each. subinterval; something that is "too random" and unacceptable in most cases. If one had an application where extreme uniformity was essential and some other characteristics of randomess were of minor importance, the generator $\lambda=2^{12}+1$ and $\mu=1$ would merit consideration.

The frequency chi-square values for $M I$ and $M 2$ obtained in the extended tests were all within the 95 per cent confidence interval.

\section{Matrix Test.}

The question arises if there is undue correlation between certain numbers in the sequence. M. L. Juncosa [6] proposed the test whereby one forms a $K$ by $K$ matrix whose elements $K_{i j}$ represent the number of times a number in the $i$ th interval is tollowed by a number in the $j$ th interifal. Equal values are expected for all matrix elements, and a chi-square value is computed and compared with the expected chi-square distribution with $K^{2}-1$ degrees of freedom. For our teot we delected a 32 by 32 matrix. This matrix has 1024 elements and thus the test is somewhat similar to our frequency test. Table 2 shows the results of this test on the sequences formed by our selected parameters. : The results are similar to those in Table 1, except that two additional generators fail to pass this test, namely $\lambda=2^{16}+\cdot 1$ with $\mu=1$, and $\lambda=2^{17}+1$ with $\mu=1$. It is interesting to note that chariging the $\mu$ value makes $\lambda=2^{17}+\cdots$ an acceptable multiplier as far as this test is concerned. The corresponding chi-square values from the extended tests on $M I$ and M2 were all.within the 95 per cent confidence interval, with the exception of 
one value of 1119.0 for Ml which barely exceeds the upper limit of 1113.5 (one even expects this number to be exceeded 2.5 per cent of the time).

\section{Auto-correlation Coefficient}

The auto-correlation coefficient [5] is defined by

$$
c_{h}=\frac{1}{N} \sum_{i=1}^{N} x_{i} \cdot x_{i+h}
$$

and Iikewise serves as a measure of the independence of the numbers $x_{n}$ of the sequence. For a truly random sample the values of $C_{h}$ are approximately normalIy distributed about the mean $=1 / 4$ for $h>0$, and mean $=1 / 3$ for $h=0$, with a standard deviation $=.3 / \sqrt{\mathrm{N}}$ in iboth cases.

With choices of $\lambda$ with the form $2^{a}+1$, one may be concerned about every 2nd, 4th, 8th - - etc. numbers (and others for that matter) being correlated. This concern is considered in more detail in a later test, but we will. mention here that in some Nonte Carlo application every $j^{\prime \text { th }}$ number in a sequence is associated with a particular variable.

In our test on the auto-correlation coefficient we let $h=0,1, \cdot .9$, and these coefficients are listed in Table 3. We observe that the generator, $\lambda=2^{15}+I$ with $\mu=1$, had passed the two previous tests, yet here shows the property that we were concemed about, namely that 2nd, 4 th, and 8 th numbers are unduly correlated. As in the previous test.changing the $\mu$ value for $\lambda=2^{17}+1$ is beneficial and brings the coefficients into line. Most of the coefficients for $\lambda=2^{12}+1$ and $\mu=1$ are within the limits, and this is somewhat surprising considering the results of the previous tests.

The extended teats on $M i l$ and $M 2$ showed all values for $M i l$ within the expected limits and all but 2 for $\mathrm{M} 2$, and these were below the lower init by less than .001. 
Frequency of Lengths of. Runs

An occurrence of $\mathrm{k}$ consecutive numbers forming a monotonic increasing (or decreasing) sequence which is broken by the $k+1$ st number is called a mun of length $k$. Comparing the observed frequencies of lengths of runs with expected values has been recommended as a good test for randomness [5] and we present the derivation of the expected values as follows.

We first consider an equivalent definition of a sequence of length $\mathrm{k}$. For $N$ distinct numbers $x_{1} \cdots \cdot \cdot, x_{N}$ we write an $N-1$ bitt binary sequence $S$ whose $n^{\prime}$ th term is a 0 if $x_{n}<x_{n+1}$ and a I if $x_{n}>x_{n+1}$. A subsequence of' $k$ zeroes (or ones) bracketed by ones (or zeroes) forms a sequence of length $k$. To determine the expected number of runs of length $k$ in a sequence of $N$ numbers we observe that if the $x_{i}$ are arranged in increasing sequence $x_{i l}, x_{i 2}, \cdots x_{i N}$, then all N: permutations of the subscripts are equally likely, since $P\left(x_{r}<x_{s}\right)$ $=P\left(x_{r}>x_{s}\right)=1 / 2$. 'l'heretore', an equivalent proulen is to consider the $N d$ permutations of the first $N$ integers, form the $N$ - 1 bit binary sequence $S$ as before for each permutation, and count the number of occurrences of a man of length $k$ in the whole set of $\mathbf{S}^{\prime} \mathbf{s}$. The process is lengthy but otraight-fomard. For example consider $k=1$ : in this instance four consecutive values of $x_{i}$ are needed for an "inside mu" of length $I$ and three consecutive values of $x_{i}$ are needed for an "end" mun. Examples of this are $2<3>1<4$ gives ..010.. for $S$, and $I<3>2$ which gives $01 \ldots$ for $S$. The total number of "end" runs of length 1 is $2 \cdot 2 \cdot 2\left(\begin{array}{l}N \\ 3\end{array}\right) \cdot(\mathbb{N}-3)$ ! Here the first 2 indicates two ends to choose, the second 2 corresponds to choice of up or down, and the third 2 indicates the two ways to make such a pattern with three numbers $(1<3>2$ or $2<3>1)$. The $\left(\begin{array}{l}N \\ 3\end{array}\right)$ is the number of ways to choose three numbers from $N$ to form the run, and $(\mathbb{N}-3)$ ! is the number of permutations of $N-3$. In like manner there are $2 \cdot 5 \cdot\left(\begin{array}{l}N \\ 4\end{array}\right)(N-4) !(N-3)$ "inside" muns. Here the 2 corresponds 
to choice of runs up or down, and the 5 indicates five ways to make such a pattern from four numbers.

$$
\begin{aligned}
& \text { 1. } 1<3>2<4 \\
& \text { 2. } 1<4>2<3 \\
& \text { 3. } 2<3>1<4 \\
& \text { 4. } 2<4>1<3 \\
& \text { 5. } 3<4>1<2
\end{aligned}
$$

The $\left(\begin{array}{l}N \\ 4\end{array}\right)$ is the number of ways to choose four numbers from $N$, the $(N-4) !$ is the number of permutations of $N-4$, and the (N-3).indicates the number of places the patterm could appear in the sequence S. Adding the total "end" runs and the total "inside" runs and dividing by $\mathbb{N}$ !, the total number of sequences $S$, gives the expected number of rins of length $i$. We define $A_{N}^{i}$ to be the expected number of runs $i$ in a sequence of length.N. Then

$$
A_{N}^{I}=\frac{\left(2 \cdot 2: 2 \cdot\left(\begin{array}{l}
N \\
3
\end{array}\right)(N-3) !+2 \cdot 5\left(\begin{array}{l}
N \\
4
\end{array}\right)(N-4) !(N-3)\right)}{N !}
$$

Recalling that $\left(\begin{array}{l}\mathrm{N} \\ 3\end{array}\right)=\frac{\mathbb{N}(\mathrm{N}-1)(\mathrm{N}-2)}{3 !}=\frac{\mathrm{N} !}{3 !(\mathrm{N}-3 !}$

and substituting for $\left(\begin{array}{l}\mathbb{N} \\ 3\end{array}\right)$ and $\left(\begin{array}{l}\mathbb{N} \\ 4\end{array}\right)$ in (3.1), and cancelling the N!, the (N-3)!, and the $(\mathrm{N}-4)$ ! we obtain

$$
A_{\mathrm{N}}^{I}=\frac{8}{3 !}+\frac{10(\mathrm{~N}-3)}{4 !}=\frac{32+10 \mathrm{~N}-30}{24}=\frac{5 \mathrm{~N}+1}{12}
$$

as the expected nuliver of runs of length $I$ in a sequence of $\mathrm{N}$ random numbers. The formula for a mun of length $k$ is

$$
A_{N}^{k}=\frac{2 \cdot 2(k+1)\left(\begin{array}{c}
N \\
k+2
\end{array}\right)(N-k-2) !+2\left(k+(k+1)^{2}\right)\left(\begin{array}{c}
N \\
k+2
\end{array}\right)(N-k-3) !(N-k-2)}{N !} .
$$


Here the $(\dot{k}+1)$ in the first term corresponds to the number of ways $k+l$ integers can be arranged in the prescribed pattern for an "end" rin, and the $\left(k+(k+1)^{2}\right)$ in the second term is the number of ways $k+3$ integers can be combined to form the prescribed pattern for an "inside" mun. The remaining factors have the same significance as for the case $k=1$. Carrying out the necessary algebra we find the simplified formula for the expected number of runs of length $k$ in a sequence of length $N$ where $k<N-1$ to be

$$
A_{N}^{k}=\frac{2\left(\left(k^{2}+3 k+1\right) N_{n}-\left(k^{3}+3 k^{2}-k-4\right)\right)}{(k+3) !}
$$

Table 4 compares the: observed lengths of sequences formed by the various generators with the expected values. The chi-square value is computed from the frequencies in five cells, the first four cells correspond to the lengths of mun 1, 2, 3, and 4, while the fifth cell corresponds to all lengths of mun greater than four. Thus we compare the computed chi-square values with a chi-square distribution with four degrees of freedom.

This length of mun test is by far the most discriminating test, in the sense that this test rejects over half of the generators tested as unacceptable. Whille some of the generators would produce statistics in other tests that were questionable the statistics for these same generators are not even close to the expected values in the length of mun test.

In keeping with our previous comments on $\lambda^{\prime}=e^{17}+1$, we note that the larger $\mu$ value reduces the chi-square value by more than a factor of 300 , yet it is still not acceptable as far as this length of run test is concermed.

It was chiefly on the basis of this test that $\lambda=2^{18}+3$ with $\mu=0$ (called Ml in, our discussion) and $\lambda=2^{9}+1$ with $\mu=1$. (called $M 2$ in our discussion) were selected for more extensive testing. All of the nine additional 
chi-square values for $M l$ vere in the 95 per cent confidence interval, while two of the values for M2 exceeded 15. This is significant enough to reject M2 as a satisfactory generator.

\section{Frequencies in Subsequences}

In our discussion on the auto-correlation coefficient we were concerned about the correlation between every $j$ 'th number. We now discuss the subject further and another test for randomness.

Consider the following example. Suppose that one desires the coordinates $\left(x_{i}, y_{i}, z_{i}\right)$ of a large number of points uniformly distributed throughout the unit cuive. Then one merely uses one of the random number generators to generate a sequence of random numbers $r_{i}\left(0<r_{i}<1\right)$ and assigns the desired coordinates these values, i.e., $x_{1}=r_{1}, y_{1}=r_{2}, z_{1}=r_{3}$ and $x_{2}=r_{4}, y_{2}=r_{5}$, $z_{2}=r_{6}$, etc. This is the type of application we mentioned earlier where every $j$ th number (in our example $j=3$ ) is associated with a given variable. Thus one sees that difficulties are encountered if the subsequences of a given se-quence are not random. (In our example the points would not be uniformly distributed.)

To test for this randomness of subsequences, one sets up $j$ tables, each with $K$ subintervals, and tallies every $j$ th number of the sequence in the $j$ th table as we did in the frequency test. Table 5 lists the chi-square values of the frequencies in the subintervals for each of the $j$ tables where $j=8$. That is, the lst, 9 th, $17 \mathrm{th}, \ldots$ numbers are tallied in the table or cell corresponding to the lst subsequence, and the 2 nd, 10th, 18th, $\cdots$ numbers are tallied in the cell for the and subsequence, etc. For this test the initial random number was $24232366751_{8}$ and the sample size was 81,920 . These are the two exceptions that were mentioned in the discussion regarding the computer program. However, 
with the sample size of $81,920, \ddot{j}=8$ tables, and $K=1024$ subintervals we have the same expected values as in the regular frequency test.

This is a rather time consuming test and thus we only used it for $j=8$ and the generator $\lambda=2^{18}+3$ with $\mu=0$. It would be advisable to repeat this test for a different value of $j$ if one had an application similar to the one above where every $j$ 'th number is associated with a particular parameter.

Notice that all of the chi-square values are within the 95 per cent confidence interval.

This concludes our series of tests.

\section{Conclusions}

The length of run test is the most powerful of the foregoing tests. It rejected the most generator parameters as unsatisfactory, and rejected all the parameters that were rejected by any of the other tests.

On the basis of these tests, the multiplicative method is superior to the mixed method, and the multiplier $\lambda=2^{18}+3$ forms a satisfactory generator for the multiplicative method

$$
x_{i+1}=\lambda x_{i} \quad\left(\text { Mod } 2^{35}\right) \text {. }
$$

The following subroutine coded in the FAP computer language can be used on the IBM $709,7090,7040$ computers to obtain random numbers from the above sequence.

\begin{tabular}{|c|c|c|c|}
\hline 1 & KAND & $L D Q$ & $=\phi 1000003$ \\
\hline 2 & & $M F Y$ & $R N$ \\
\hline 3 & & STQ & $\mathrm{RN}$ \\
\hline 4 & & CLA & $\mathrm{RN}$ \\
\hline 5 & & TRA. & 1,4 \\
\hline 6 & RN & $\ddot{C} \mathrm{CT}$ & 123456227651 \\
\hline
\end{tabular}

Instruction number 4 can be omitted if the random number is not needed in the accumulator, and instruction number 5 can be modified for various types of 
return linkage. To obtain a floating point number replace instruction number 4 with the following three.

$\begin{array}{ll}\text { CLA } & =\phi 200 \\ \text { LLS } & 27 \\ \text { FAD } & =\varnothing 200000000000\end{array}$


TABLE 1.--Comparision of Chi-square values of frequencies in 1024 subintervals with generator parameters ${ }^{\text {a }}$

\begin{tabular}{|c|c|c|c|c|c|}
\hline \multicolumn{2}{|c|}{ Generator Parameters } & \multirow{2}{*}{$\begin{array}{l}\text { Chi-square of } \\
\text { Frequencies }\end{array}$} & \multicolumn{2}{|c|}{ Generator Parameters } & \multirow{2}{*}{$\begin{array}{c}\text { Chi-square of } \\
\text { Frequencies }\end{array}$} \\
\hline$\lambda$ & $\mu$ & & $\lambda$ & $\mu$ & \\
\hline $2^{7}+1$ & 1 & $\begin{array}{r}1,036.6 \\
956.0 \\
1,004.2\end{array}$ & $2^{16}+1$ & 1 & $\begin{array}{r}1,073.2 \\
990.4 \\
1,045.6\end{array}$ \\
\hline $2^{8}+1$ & 1 & $\begin{array}{r}1,002.4 \\
0.41 .9 \\
1,040.4\end{array}$ & $2^{17}+1$ & 1 & $\begin{array}{r}1,014.0 \\
976.2 \\
1,020.0\end{array}$ \\
\hline $2^{9}+1$ & 1. & $\begin{array}{l}1,025.2 \\
1,036.8 \\
1,040.4\end{array}$ & $2^{17}+1$ & $\mathrm{~b}$ & $\begin{array}{r}954.6 \\
1,009.6 \\
1,070.2\end{array}$ \\
\hline $2^{10}+1$ & 1 & $\begin{array}{r}965.4 \\
1,040.8 \\
953.8\end{array}$ & $2^{18}+1$ & 1 & $\begin{array}{r}928.0 \\
954.6 \\
962.8\end{array}$ \\
\hline $2^{11}+1$ & 1 & $\begin{array}{r}1,032.2 \\
1,104.0 \\
962.6\end{array}$ & $2^{19}+1$ & 1 & $\begin{array}{l}847.0 \\
856.2 \\
883.8\end{array}$ \\
\hline $2^{12}+1$ & 1 & $\begin{array}{l}0.0 \\
0.0 \\
0.0\end{array}$ & $2^{34}+1$ & $\perp$ & $\begin{array}{l}5,232,640.0 \\
5,232,640.0 \\
5,232,640.0\end{array}$ \\
\hline $2^{2} 13+1$ & 1 & $\begin{array}{r}931.0 \\
913.8 \\
1,051.2\end{array}$ & $2^{18}+3$ & 0 & $\begin{array}{r}1,106.0 \\
1,005.8 \\
96^{\prime} \mathrm{c} .8\end{array}$ \\
\hline $2^{14}+1$ & 1 & $\begin{array}{l}1,044.4 \\
1,107.0 \\
1,072.4\end{array}$ & 110604716258 & 0 & $\begin{array}{r}1,003.2 \\
999.6 \\
962.6\end{array}$ \\
\hline $2^{15}+1$ & 1 & $\begin{array}{r}911.2 \\
1,030.4 \\
956.2\end{array}$ & 3432772446158 & 0 & $\begin{array}{r}1,022.4 \\
990.6 \\
1,025.4\end{array}$ \\
\hline
\end{tabular}

Data is for three samples of 10,240 for each set of parameters. The 95 per cent confidence interval for the Chi-square distribution with 1023 degrees of freedom is $936.3 \leq x^{2} \leq 1113.5$.

b $\mu=1230452101_{8}$ 
TABLE 2.--Comparision of Chi-square values of frequencies in $32 \times 32$ matrix with generator parameters ${ }^{a}$

\begin{tabular}{|c|c|c|c|c|c|}
\hline \multicolumn{2}{|c|}{ Generator Parameters } & \multirow{2}{*}{$\begin{array}{l}\text { Chi-square of } \\
\text { Frequencies }\end{array}$} & \multicolumn{2}{|c|}{ Generator Parameters } & \multirow{2}{*}{$\begin{array}{c}\text { Chi-square of } \\
\text { Frequencies }\end{array}$} \\
\hline$\lambda$ & $\mu$ & & $\bar{\lambda}$ & $\mu$ & \\
\hline $2^{7}+1$ & 1 & $\begin{array}{r}1,058.0 \\
968.0 \\
1,104.8\end{array}$ & $2^{16}+1$ & 1 & $\begin{array}{l}20,191.2 \\
13,830.6 \\
14,239: 4\end{array}$ \\
\hline $2^{8}+1$ & 1 & $\begin{array}{r}985.8 \\
1,029.4 \\
1,054.2\end{array}$ & $2^{17}+1$ & 1 & $\begin{array}{l}75,676.0 \\
71,160.6 \\
71,274.8\end{array}$ \\
\hline $2^{9}+1$ & 1 & $\begin{array}{l}1,008.8 \\
1,031.4 \\
1,073.0\end{array}$ & $2^{17}+1$ & $\mathrm{~b}$ & $\begin{array}{r}1,004.2 \\
1,055.8 \\
992.0\end{array}$ \\
\hline $2^{10}+1$ & 1 & $\begin{array}{r}942.0 \\
972.8 \\
1,019.0\end{array}$ & $2^{18}+1$ & 1 & $\begin{array}{l}97,742.8 \\
97,151.8 \\
97,978.4\end{array}$ \\
\hline $2^{11}+1$ & 1 & $\begin{array}{r}1,029.6 \\
1,074.8 \\
977.8\end{array}$ & $2^{19}+1$ & 1 & $\begin{array}{l}49,790.6 \\
49,572.8 \\
4.9,991.8\end{array}$ \\
\hline $2^{12}+1$ & 1 & $\begin{array}{l}0.0 \\
0.0 \\
0.0\end{array}$ & $2^{34}+1$ & 1 & $\begin{array}{l}2,610,688.0 \\
2,611,200.0 \\
2,611,200.0\end{array}$ \\
\hline $2^{13}+1$ & 1 & $\begin{array}{r}1,015.8 \\
914.0 \\
1,048.2\end{array}$ & $2^{18}+3$ & 0 & $\begin{array}{r}1,023.2 \\
1,040.8 \\
980.2\end{array}$ \\
\hline $2^{14}+1$ & 1 & $\begin{array}{r}1,045.8 \\
955.2 \\
907.2\end{array}$ & 110604716258 & 0 & $\begin{array}{r}964.8 \\
1,074.4 \\
1,010.8\end{array}$ \\
\hline $2^{15}+1$ & 1 & $\begin{array}{r}1,004.4 \\
939.4 \\
944.8\end{array}$ & 3432772446158 & 0 & $\begin{array}{l}1,017.4 \\
1,051.2 \\
1,101.2\end{array}$ \\
\hline
\end{tabular}

Data is for three samples of 10,240 for each set of parameters. The 95 per cent confidence interval for the Chi-square distribution with 1023 degrees of freedom is $936.3 \leq x^{2} \leq 1113.5$.

b $\mu=1230452101_{8}$ 
TABLE 3.--Auto-correlation coefficients ${ }^{2}$

$$
c_{h}=\frac{i}{N} \sum_{i=1}^{N} x_{i} \cdot x_{i+h}
$$

\begin{tabular}{|c|c|c|c|c|c|c|c|c|c|c|c|}
\hline \multicolumn{2}{|c|}{$\begin{array}{l}\text { Generator } \\
\text { Parameters }\end{array}$} & \multicolumn{10}{|c|}{$h$ values } \\
\hline$\lambda$ & $\mu$ & 0 & 1 & 2 & 3 & 4 & 5 & 6 & 7 & 8 & 9 \\
\hline \multirow{2}{*}{$2^{7}+i$} & \multirow[b]{2}{*}{1} & 3358 & 2548 & 2540 & 2538 & 2546 & 2528 & 2537 & 2538 & 2536 & 2544 \\
\hline & & $\begin{array}{l}3304 \\
3337\end{array}$ & 2474 & 2452 & 2464 & . 2484 & 2470 & 2466 & 2477 & 2476 & 2470 \\
\hline \multirow{4}{*}{$2^{8}+1$} & \multirow{4}{*}{1} & & & & & & & & & & \\
\hline & & 3317 & 2481 & 2495 & 2480 & 2482 & 2478 & 2475 & 2475 & 2500 & 2482 \\
\hline & & 3318 & $24: 70$ & 2482 & 2483 & 2487 & 2474 & 2476 & 2477 & 2491 & 2485 \\
\hline & & 3322 & 2471 & 2470 & 2489 & 2485 & 2471 & 2480 & 2478 & 2464 & 2490 \\
\hline \multirow{3}{*}{$2^{9}+1$} & \multirow{3}{*}{1} & 3305 & 2462 & 2461 & 2450 & 2464 & 2463 & 2469 & 2469 & 2454 & 2480 \\
\hline & & 3326 & 2507 & 2498 & 2500 & 2493 & 2488 & 2489 & 2480 & 2490 & 2484 \\
\hline & & 3343 & 2532 & 2513 & 2523 & 2532 & 2518 & 2516 & 2525 & 2537 & 2527 \\
\hline \multirow{3}{*}{$2^{10}+1$} & \multirow{3}{*}{1} & 3354 & 2513 & 2517 & 2507 & 2528 & 2522 & 2523 & 2531 & 2530 & 2527 \\
\hline & & 3364 & 2543 & 2556 & 2545 & 2551 & 2537 & 2537 & 2550 & 2530 & 2538 \\
\hline & & 3384 & 2553 & 2547 & 2560 & 2556 & 2557 & 2549 & 2560 & 2552 & 2550 \\
\hline \multirow{3}{*}{$2^{I I}+1$} & \multirow{3}{*}{1} & 3357 & 2528 & 2537 & 2543 & .2541 & 2538 & 2526 & 2529 & 2536 & 2535 \\
\hline & & 3273 & 2430 & 2449 & 2441 & 2444 & 2424 & 2428 & 2433 & 2424 & 2429 \\
\hline & & 3384 & 2553 & 2547 & 2545 & 2541 & 2535 & 2543 & 2557 & 2530 & 2550 \\
\hline \multirow{3}{*}{$2^{12}+1$} & \multirow{3}{*}{1} & 3327 & 2480 & 2486 & 2494 & 2463 & 2407 & 2483 & 2487 & 2480 & 2486 \\
\hline & & 3420 & 2571 & 2567 & 2554 & 2534 & 2567 & 2575 & 2564 & 2566 & 2560 \\
\hline & & 3334 & 2526 & 2500 & 2508 & 2498 & 2498 & 2521 & 2506 & 2491 & 2511 \\
\hline \multirow{3}{*}{$2^{13}+i$} & \multirow{3}{*}{1} & 3352 & 2511 & 2555 & .2517 & 2521 & 2516 & 2548 & 2525 & 2452 & 2520 \\
\hline & & 3331 & 2497 & 2507 & 2487 & 2497 & 2493 & 251 & 2498 & 2447 & 2498 \\
\hline & & 3337 & 2488 & 2512 & 2484 & 2492 & 2432 & 2530 & 2482 & 2429 & 2493 \\
\hline \multirow{3}{*}{$2^{14}+1$} & \multirow{3}{*}{1} & 3396 & 2578 & 2606 & 2562 & 2514 & 2567 & 2555 & 2581 & 2496 & 2570 \\
\hline & & 3315 & 2475 & 2515 & 2478 & 2437 & 2488 & 2481 & 2491 & 2374 & 2583 \\
\hline & & 3340 & 2503 & 2541 & 2509 & 2460 & 2511 & 2532 & 2502 & 2373 & 2517 \\
\hline \multirow{3}{*}{$2^{15}+1$} & \multirow{3}{*}{1} & 3324 & 2502 & 2668 & 2495 & 2671 & 2490 & 2458 & 2485 & 2267 & 2486 \\
\hline & & 3339 & 2.501 & 2660 & 2509 & 2736 & 2509 & 242 & 2513 & 2270 & 25.12 \\
\hline & & 3335 & 2505 & 2665 & 2510 & 2743 & 2501 & 2403 & 2508 & 2314 : & 24.99 \\
\hline
\end{tabular}


TABLE 3.--Continued

\begin{tabular}{|c|c|c|c|c|c|c|c|c|c|c|c|}
\hline \multicolumn{2}{|c|}{$\begin{array}{l}\text { Generator } \\
\text { Parameters }\end{array}$} & \multicolumn{10}{|c|}{$h$ values } \\
\hline$\lambda$ & $\mu$ & 0 & 1 & 2 & 3 & 4 & 5 & 6 & 7 & 8 & 9 \\
\hline $2^{16}+1$ & 1 & $\begin{array}{l}3340 \\
3337 \\
3366\end{array}$ & $\begin{array}{l}2499 \\
2501 \\
2518\end{array}$ & $\begin{array}{l}2267 \\
2272 \\
2323\end{array}$ & $\begin{array}{l}2514 \\
2502 \\
2529\end{array}$ & $\begin{array}{l}2796 \\
2828 \\
2763\end{array}$ & $\begin{array}{l}2495 \\
2506 \\
2539\end{array}$ & $\begin{array}{l}2429 \\
2342 \\
2300\end{array}$ & $\begin{array}{l}2522 \\
2493 \\
2534\end{array}$ & $\begin{array}{l}2414 \\
2554 \\
2588\end{array}$ & $\begin{array}{l}2499 \\
2497 \\
2530\end{array}$ \\
\hline $2^{17}+1$ & 1 & $\begin{array}{l}3339 \\
3340 \\
3349\end{array}$ & $\begin{array}{l}2420 \\
2463 \\
2529\end{array}$ & $\begin{array}{r}2473 \\
.2414 \\
2421\end{array}$ & $\begin{array}{l}2597 \\
2575 \\
2426\end{array}$ & $\begin{array}{l}2377 \\
2132 \\
2138\end{array}$ & $\begin{array}{l}2564 \\
2418 \\
2599\end{array}$ & $\begin{array}{l}2529 \\
2497 \\
2500\end{array}$ & $\begin{array}{l}2444 \\
2574 \\
2456\end{array}$ & $\begin{array}{l}2134 \\
2713 \\
2740\end{array}$ & $\begin{array}{l}2500 \\
2473 \\
2558\end{array}$ \\
\hline $2^{17}+1$ & $b$ & $\begin{array}{l}3307 \\
3323 \\
3364\end{array}$ & $\begin{array}{l}2505 \\
2494 \\
2527\end{array}$ & $\begin{array}{l}2493 \\
2488 \\
2530\end{array}$ & $\begin{array}{l}2483 \\
2492 \\
2542\end{array}$ & $\begin{array}{l}2464 \\
2472 \\
2542\end{array}$ & $\begin{array}{l}2488 \\
2492 \\
2523\end{array}$ & $\begin{array}{r}2478 \\
2482 \\
2530\end{array}$ & $\begin{array}{l}2491 \\
2504 \\
2520\end{array}$ & $\begin{array}{l}2492 \\
2492 \\
2521\end{array}$ & $\begin{array}{l}2481 \\
2494 \\
2544\end{array}$ \\
\hline $2^{18}+1$ & 1 & $\begin{array}{l}3337 \\
3337 \\
3327\end{array}$ & $\begin{array}{l}2177 \\
2311 \\
2495\end{array}$ & $\begin{array}{l}2374 \\
2129 \\
2117\end{array}$ & $\begin{array}{l}2891 \\
2792 \\
2190\end{array}$ & $\begin{array}{l}2131 \\
2709 \\
2717\end{array}$ & $\begin{array}{l}2710 \\
2164 \\
2876\end{array}$ & $\begin{array}{l}2599 \\
2463 \\
2434\end{array}$ & $\begin{array}{l}2239 \\
2776 \\
2203\end{array}$ & $\begin{array}{r}2709 \\
2415 \\
2425\end{array}$ & $\begin{array}{l}2460 \\
2351 \\
2635\end{array}$ \\
\hline $2^{19}+1$ & 1 & $\begin{array}{l}3331 \\
3319 \\
3369\end{array}$ & $\begin{array}{l}2369 \\
2110 \\
2158\end{array}$ & $\begin{array}{l}2126 \\
2691 \\
2759\end{array}$ & $\begin{array}{l}2593 \\
2444 \\
2475\end{array}$ & $\begin{array}{l}2703 \\
2397 \\
2466\end{array}$ & $\begin{array}{l}2464 \\
2582 \\
2627\end{array}$ & $\begin{array}{l}2467 \\
2437 \\
2491\end{array}$ & $\begin{array}{l}2473 \\
2452 \\
2500\end{array}$ & $\begin{array}{l}2433 \\
2539 \\
2603\end{array}$ & $\begin{array}{l}2580 \\
2452 \\
2487\end{array}$ \\
\hline $2^{34}$ & $I$ & $\begin{array}{l}3950 \\
3950 \\
3950\end{array}$ & $\begin{array}{l}3324 \\
3324 \\
3324\end{array}$ & $\begin{array}{l}2699 \\
2699 \\
2699\end{array}$ & $\begin{array}{l}3324 \\
3324 \\
3324\end{array}$ & $\begin{array}{l}3950 \\
3950 \\
3950\end{array}$ & $\begin{array}{l}3324 \\
3324 \\
3324\end{array}$ & $\begin{array}{l}2699 \\
2699 \\
2699\end{array}$ & $\begin{array}{l}3324 \\
3324 \\
3324\end{array}$ & $\begin{array}{l}3950 \\
3950 \\
3950\end{array}$ & $\begin{array}{l}3324 \\
3324 \\
3324\end{array}$ \\
\hline $2^{18}+3$ & 0 & $\begin{array}{l}3344 \\
3353 \\
3319\end{array}$ & $\begin{array}{l}2513 \\
2530 \\
2492\end{array}$ & $\begin{array}{l}2521 \\
2517 \\
2504\end{array}$ & $\begin{array}{l}2519 \\
2519 \\
2477\end{array}$ & $\begin{array}{l}2517 \\
2515 \\
2486\end{array}$ & $\begin{array}{l}2523 \\
2525 \\
2487\end{array}$ & $\begin{array}{l}2521 \\
2520 \\
2487\end{array}$ & $\begin{array}{l}2521 \\
2515 \\
2478\end{array}$ & $\begin{array}{l}2512 \\
2525 \\
2499\end{array}$ & $\begin{array}{l}2510 \\
2523 \\
2492\end{array}$ \\
\hline C & 0 & $\begin{array}{l}3374 \\
3379 \\
3359\end{array}$ & $\begin{array}{l}2533 \\
2563 \\
2518\end{array}$ & $\begin{array}{l}2524 \\
2567 \\
2522\end{array}$ & $\begin{array}{l}2517 \\
2552 \\
2504\end{array}$ & $\begin{array}{l}2515 \\
2549 \\
2523\end{array}$ & $\begin{array}{l}2530 \\
2562 \\
2526\end{array}$ & $\begin{array}{l}2518 \\
2561 \\
2518\end{array}$ & $\begin{array}{l}2535 \\
2548 \\
2536\end{array}$ & $\begin{array}{l}2530 \\
2564 \\
2521\end{array}$ & $\begin{array}{l}2545 \\
2545 \\
2511\end{array}$ \\
\hline $\mathrm{d}$ & 0 & $\begin{array}{l}3372 \\
3331 \\
3362\end{array}$ & $\begin{array}{l}2552 \\
2501 \\
2541\end{array}$ & $\begin{array}{l}2548 \\
2512 \\
2545\end{array}$ & $\begin{array}{l}2544 \\
2506 \\
2550\end{array}$ & $\begin{array}{l}2536 \\
2507 \\
2554\end{array}$ & $\begin{array}{l}2543 \\
2504 \\
2531\end{array}$ & $\begin{array}{l}2543 \\
2503 \\
2535\end{array}$ & $\begin{array}{l}2553 \\
2518 \\
2545\end{array}$ & $\begin{array}{l}2562 \\
2498 \\
2548\end{array}$ & $\begin{array}{l}2540 \\
2511 \\
2525\end{array}$ \\
\hline
\end{tabular}

$a_{A l l}$ values of $C_{h}$ are times $10^{-4}$. The expected value of $c_{0}$ is .333 \pm .006 and of $C_{h}$ is $.250 \pm .006$ for $h>0$. The .006 represents two standard deviations and $N=10,231$.

$$
\begin{aligned}
& \text { b } \mu=123045201 i_{8} \\
& \text { c. } \lambda=110604716258 \\
& \text { d } \lambda=343277244615_{8}
\end{aligned}
$$


TABLE 4.-. Lengths of runs ${ }^{a}$

\begin{tabular}{|c|c|c|c|c|c|c|c|c|c|}
\hline \multicolumn{2}{|c|}{$\begin{array}{l}\text { Generator } \\
\text { Parameters }\end{array}$} & \multirow{2}{*}{$\begin{array}{c}x^{2} \\
\text { Chi-square }\end{array}$} & \multicolumn{7}{|c|}{ Lengths of Runs } \\
\hline$\lambda$ & $\mu$ & & 1 & 2 & 3 & 4 & 5 & 6 & $\geq 7$ \\
\hline & & \multicolumn{8}{|c|}{ Expected Values } \\
\hline & & $\begin{array}{l}.48 \leq x^{2} \\
\leq 11.14\end{array}$ & 4266.8 & 1877.1 & 540.31 & 117.8 & 20.8 & 3.1 & .4 \\
\hline & & \multicolumn{8}{|c|}{ Observed Values } \\
\hline $2^{7}+1$ & 1 & $\begin{array}{r}6.73 \\
10.81 \\
1.18\end{array}$ & $\begin{array}{l}4234 \\
4281 \\
4251\end{array}$ & $\begin{array}{l}1836 \\
1893 \\
1852\end{array}$ & $\begin{array}{l}579 \\
559 \\
548\end{array}$ & $\begin{array}{l}137 \\
112 \\
126\end{array}$ & $\begin{array}{r}27 \\
8 \\
21 .\end{array}$ & $\begin{array}{l}5 \\
1 \\
5\end{array}$ & $\begin{array}{l}0 \\
0 \\
0\end{array}$ \\
\hline $2^{8}+1$ & 1 & $\begin{array}{l}6.03 \\
2.59 \\
4.87\end{array}$ & $\begin{array}{l}4345 \\
4246 \\
4234\end{array}$ & $\begin{array}{l}1831 \\
1918 \\
1927\end{array}$ & $\begin{array}{l}519 \\
540 \\
516\end{array}$ & $\begin{array}{l}135 \\
108 \\
111\end{array}$ & $\begin{array}{l}23 \\
18 \\
29\end{array}$ & $\begin{array}{l}2 \\
2 \\
1\end{array}$ & $\begin{array}{l}1 \\
0 \\
1\end{array}$ \\
\hline $2^{9}+1$ & 1 & $\begin{array}{l}5.07 \\
5.50 \\
7.66\end{array}$ & $\begin{array}{l}4302 \\
4283 \\
4163\end{array}$ & $\begin{array}{l}1918 \\
1841 \\
1861\end{array}$ & $\begin{array}{l}533 \\
571 \\
583\end{array}$ & $\begin{array}{l}102 \\
102 \\
125\end{array}$ & $\begin{array}{l}15 \\
23 \\
14\end{array}$ & $\begin{array}{l}3 \\
5 \\
3\end{array}$ & $\begin{array}{l}0 \\
1 \\
2\end{array}$ \\
\hline $2^{10}+1$ & 1 & $\begin{array}{r}8.35 \\
14.20 \\
2.40\end{array}$ & $\begin{array}{l}4363 \\
4261 \\
4212\end{array}$ & $\begin{array}{l}1787 \\
1951 \\
1920\end{array}$ & $\begin{array}{l}553 \\
549 \\
529\end{array}$ & $\begin{array}{r}131 \\
88 \\
113\end{array}$ & $\begin{array}{l}20 \\
15 \\
19\end{array}$ & $\begin{array}{l}3 \\
0 \\
6\end{array}$ & $\begin{array}{l}0 \\
0 \\
2\end{array}$ \\
\hline $2^{11}+1$ & 1 & $\begin{array}{r}8.09 \\
9.83 \\
10.78\end{array}$ & $\begin{array}{l}4266 \\
4340 \\
4265\end{array}$ & $\begin{array}{l}1938 \\
185.5 \\
1926\end{array}$ & $\begin{array}{r}540 \\
526 \\
.534\end{array}$ & $\begin{array}{r}92 \\
105 \\
89\end{array}$ & $\begin{array}{l}19 \\
33 \\
31\end{array}$ & $\begin{array}{l}2 \\
3 \\
0\end{array}$ & $\begin{array}{l}0 \\
1 \\
1\end{array}$ \\
\hline $2^{12}+1$ & 1 & $\begin{array}{r}105.70 \\
109.31 \\
88.27\end{array}$ & $\begin{array}{l}4283 \\
4355 \\
4.1 .24\end{array}$ & $\begin{array}{l}2040 \\
1977 \\
2005\end{array}$ & $\begin{array}{l}424 \\
423 \\
432\end{array}$ & $\begin{array}{r}66 \\
71 \\
172\end{array}$ & $\begin{array}{l}30 \\
34 \\
3 ?\end{array}$ & $\begin{array}{l}14 \\
13 \\
1 ?\end{array}$ & $\begin{array}{l}13 \\
15 \\
16\end{array}$ \\
\hline $2^{13}+1$ & 1 & $\begin{array}{r}136.70 \\
95.90 \\
78.50\end{array}$ & $\begin{array}{l}4444 \\
4414 \\
4411\end{array}$ & $\begin{array}{l}2013 \\
2011 \\
1972\end{array}$ & $\begin{array}{l}367 \\
378 \\
422\end{array}$ & $\begin{array}{l}69 \\
81 \\
67\end{array}$ & $\begin{array}{l}26 \\
22 \\
18\end{array}$ & $\begin{array}{l}5 \\
1 \\
5\end{array}$ & $\begin{array}{l}26 \\
24 \\
24\end{array}$ \\
\hline $2^{14}+1$ & 1 & $\begin{array}{l}179.25 \\
225.81 \\
168.51\end{array}$ & $\begin{array}{l}4425 \\
4481 \\
4461\end{array}$ & $\begin{array}{l}1966 \\
1976 \\
1979\end{array}$ & $\begin{array}{l}373 \\
351 \\
351\end{array}$ & $\begin{array}{l}74 \\
68 \\
84\end{array}$ & $\begin{array}{l}35 \\
44 \\
34\end{array}$ & $\begin{array}{l}14 \\
16 \\
13\end{array}$ & $\begin{array}{l}25 \\
19 \\
21\end{array}$ \\
\hline $2^{15}+1$ & 1 & $\begin{array}{l}349.30 \\
266.22 \\
281.09\end{array}$ & $\begin{array}{l}5054 \\
4,920 \\
4899\end{array}$ & $\begin{array}{l}1864 . \\
1881 \\
1989\end{array}$ & $\begin{array}{l}253 \\
289 \\
244\end{array}$ & $\begin{array}{l}171 \% \\
172 \\
147\end{array}$ & $\begin{array}{l}0 \\
0 \\
8\end{array}$ & $\begin{array}{l}0 \\
0 \\
0\end{array}$ & $\begin{array}{l}0 \\
0 \\
0\end{array}$ \\
\hline $2^{16}+1$ & 1 & $\begin{array}{r}1,022.00 \\
1,021.60 \\
884.77\end{array}$ & $\begin{array}{l}2765 \\
2822 \\
2987\end{array}$ & $\begin{array}{l}2798 \\
2790 \\
2733\end{array}$ & $\begin{array}{l}528 \\
569 \\
571\end{array}$ & $\begin{array}{l}73 \\
32 \\
18\end{array}$ & $\begin{array}{l}0 \\
0 \\
0\end{array}$ & $\begin{array}{l}0 \\
0 \\
0\end{array}$ & $\begin{array}{l}0 \\
0 \\
0\end{array}$ \\
\hline
\end{tabular}


TABLE 4.-- - Continued

\begin{tabular}{|c|c|c|c|c|c|c|c|c|c|}
\hline \multicolumn{2}{|c|}{$\begin{array}{l}\text { Generator } \\
\text { Parameters }\end{array}$} & \multirow{2}{*}{$\begin{array}{c}x^{2} \\
\text { Chi-square }\end{array}$} & \multicolumn{2}{|l|}{$\therefore$} & \multicolumn{2}{|c|}{ Lengths of Runs } & $\vdots$ & \multicolumn{2}{|l|}{$\cdot$} \\
\hline$\lambda$ & $\mu$ & & 1 & 2 & $-3 \quad \cdots$ & 4 & 5 & 6 & $\geq 7$ \\
\hline \multirow[b]{2}{*}{$n$} & & \multicolumn{8}{|c|}{ Expected Values } \\
\hline & & $\begin{array}{l}48 . \leq x^{2} \\
\leq 11.14\end{array}$ & 4266.8 & 1877.1 & 540.31 & 117.8 & 20.8 & 3.1 & .4 \\
\hline$\therefore$ & & \multicolumn{8}{|c|}{ Observed Values } \\
\hline $2^{17}+1$ & 1 & $\begin{array}{r}1,682.70 \\
1,074.10 \\
881.20\end{array}$ & $\begin{array}{l}3802 \\
3276 \\
3018\end{array}$ & $\begin{array}{l}3215 \\
2965 \\
2166\end{array}$ & $\begin{array}{r}2 \\
344 \\
962\end{array}$ & $\begin{array}{l}0 \\
0 \\
0\end{array}$ & $\begin{array}{l}0 \\
0 \\
0\end{array}$ & $\begin{array}{l}0 \\
0 \\
0\end{array}$ & $\begin{array}{l}0 \\
0 \\
0\end{array}$ \\
\hline $2^{17}+1$ & c & $\begin{array}{l}204.29 \\
221.81 \\
198.96\end{array}$ & $\begin{array}{l}3819 \\
3808 \\
3887\end{array}$ & $\begin{array}{l}2262 \\
2255 \\
2226\end{array}$ & $\begin{array}{l}578 \\
600 \\
597 .\end{array}$ & $\begin{array}{l}40 \\
30 \\
27\end{array}$ & $\begin{array}{l}0 \\
0 \\
0\end{array}$ & $\begin{array}{l}0 \\
0 \\
0\end{array}$ & $\begin{array}{l}0 \\
0 \\
0\end{array}$ \\
\hline $2^{18}+1$ & 1 & $\begin{array}{r}1,107 \cdot 90 \\
1,752: 10 \\
12,951.00\end{array}$ & $\begin{array}{l}4830 \\
2967 \\
2168\end{array}$ & $\begin{array}{r}2698 \\
1627 \\
0\end{array}$ & $\begin{array}{r}4 \\
1339 \\
840\end{array}$ & $\begin{array}{r}0 \\
0 \\
1080\end{array}$ & $\begin{array}{r}0 \\
0 \\
246\end{array}$ & $\begin{array}{r}r 0 \\
0 \\
0\end{array}$ & $\begin{array}{l}0 \\
0 \\
0\end{array}$ \\
\hline $2^{19}+1$ & I & $\begin{array}{l}2,510.50 \\
2,446.30 \\
2,602.50\end{array}$ & $\begin{array}{l}2714 \\
6984 \\
7092\end{array}$ & $\begin{array}{l}1103 \\
1627 \\
1573\end{array}$ & $\begin{array}{r}1093 \\
0 \\
0\end{array}$ & $\begin{array}{r}471 \\
0 \\
0\end{array}$ & $\begin{array}{r}31 \\
0 \\
0\end{array}$ & $\begin{array}{l}0 \\
0 \\
0\end{array}$ & $\begin{array}{l}0 \\
0 \\
0\end{array}$ \\
\hline $2^{34}+1$ & 1 & $\begin{array}{l}10,243.00 \\
10,21.3 .00 \\
10,243.00\end{array}$ & $\begin{array}{l}2561 \\
2561 \\
2561\end{array}$ & $\begin{array}{l}0 \\
0 \\
0\end{array}$ & $\begin{array}{l}2559 \\
2559 \\
2559\end{array}$ & $\begin{array}{l}0 \\
0 \\
0\end{array}$ & $\begin{array}{l}0 \\
0 \\
0\end{array}$ & $\begin{array}{l}0 \\
0 \\
0\end{array}$ & $\begin{array}{l}0 \\
0 \\
0\end{array}$ \\
\hline $2^{18}+3$ & 0 & $\begin{array}{l}1.89 \\
4.96 \\
7.49\end{array}$ & $\begin{array}{l}4263 \\
4203 \\
4377\end{array}$ & $\begin{array}{l}1875 \\
1889 \\
1834\end{array}$ & $\begin{array}{l}525 \\
542 \\
561\end{array}$ & $\begin{array}{l}122 \\
114 \\
101\end{array}$ & $\begin{array}{l}22 \\
30 \\
20\end{array}$ & $\begin{array}{l}5 \\
4 \\
1\end{array}$ & $\begin{array}{l}3 \\
0 \\
0\end{array}$ \\
\hline $\mathrm{d}$ & 0 & $\begin{array}{l}6.67 \\
5.34 \\
3.06\end{array}$ & $\begin{array}{l}4180 \\
4237 \\
4314\end{array}$ & $\begin{array}{l}1868 \\
1841 \\
1835\end{array}$ & $\begin{array}{l}551 \\
538 \\
559\end{array}$ & $\begin{array}{l}140 \\
137 \\
109\end{array}$ & $\begin{array}{l}18 \\
25 \\
22\end{array}$ & $\begin{array}{l}3 \\
3 \\
4\end{array}$ & $\begin{array}{l}0 \\
2 \\
1\end{array}$ \\
\hline e & 0 & $\begin{array}{l}2.19 \\
2.16 \\
4.71\end{array}$ & $\begin{array}{l}4218 \\
4296 \\
4.287\end{array}$ & $\begin{array}{l}1878 \\
1868 \\
1913\end{array}$ & $\begin{array}{l}551 \\
556 \\
532\end{array}$ & $\begin{array}{c}114 \\
107 \\
113\end{array}$ & $\begin{array}{l}26 \\
17 \\
13\end{array}$ & $\begin{array}{l}4 \\
3 \\
2\end{array}$ & $\begin{array}{l}0 \\
1 \\
0\end{array}$ \\
\hline
\end{tabular}

Data is for three samples of 10,240 for each set of parameters.

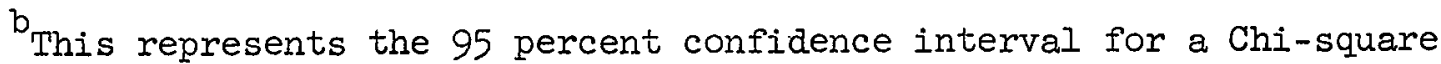
distribution with four degrees of freedom.

$$
\begin{aligned}
\text { c } & \mu=1230452101_{8} \\
\text { d } & =110604716258 \\
\text { e } & =3432772446158
\end{aligned}
$$


TABLE 5.--Chi-square values of frequencies in 1024 subintervals, for 8 subsequences of the sequence generated by using $\lambda=2^{18}+3$ and $\mu=0^{a}$

\begin{tabular}{c|c|c|c}
\hline \multirow{2}{*}{$\begin{array}{c}\text { Subsequence } \\
\text { Number }\end{array}$} & \multicolumn{3}{|c}{ Chi-square of Frequencies } \\
\cline { 2 - 4 } 1 & Sample 1 & Sample 2 & Sample 3 \\
\hline 2 & -.984 .4 & $1,069.0$ & $1,062.8$ \\
3 & $1,016.4$ & 942.4 & 925.6 \\
4 & $1,000.6$ & $1,023.2$ & $1,022.2$ \\
5 & 989.6 & $1,017.0$ & $1,055.8$ \\
6 & 936.2 & $1,010.0$ & 982.6 \\
7 & 964.2 & 990.6 & $1,084.4$ \\
8 & 966.6 & $1,054.0$ & $1,033.2$ \\
& 906.8 & 999.2 & $1,024.0$ \\
\hline
\end{tabular}

Each sample size was 81,920 or 10,240 in each subsequence. The 95 per cent confidence interval for a Chi-square distribution with 1023 degrees of freedom is $936.6 \leq x^{2} \leq 1113.5$. 
[1] Coveyou, R. R. Serial correlation in the generation of pseudo-random numbers. J. Assoc. Comput. Mach. 7 (1960) 72-74.

[2] Cramer, Herald. Mathematical methods of statistics. Princeton University Press, 1946, p. 138

[3] Greenberger, Martin. INotes on a new pseudo-random number generator: J. Assoc. Comput. Mach. 8 (1961) 163-167.

[4] Greenberger, Martin. An a priori determination of serial correlation in computer generated random numbers. Math. Comp. 15 (1961) 383-389. Also private communication to the author.

[5] Intemational Business Machines Corp. Random number generation and testing reference manual C20-8011. New York: 1959.

[6] Juncosa, M. L. Random number generation on the BRL high-speed computing machines. Ballistic Research Laboratories, Report number 855 (Aberdeen Proving Ground, 1953).

[7] Lehmer, D. H. Mathematical methods in large-scale computing units. Annals Comp. Laboratory Harvard Univ. 26 (1951) 141-146.

[8] Rotenberg, A. A new pseudo-random number generator. J. Assoc. Comput. Mach. 7 (1960) 75-77. 


\section{PHILLIPS PETROLEUM COMPANY

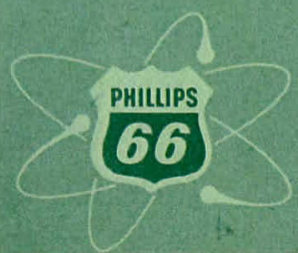

ATOMIC ENERGY DIVISION 